\title{
GÊNERO E GEOGRAFIA BRASILEIRA: UMA ANÁLISE SOBRE O TENSIONAMENTO DE UM CAMPO DE SABER.
}

\author{
GENDER AND BRAZILIAN GEOGRAPHY: AN ANALYSIS OF A \\ KNOWLEDGE FIELD TENSIONING \\ GÉNERO Y GEOGRAFÍA BRASILEÑA: UN ANÁLISIS SOBRE EL \\ TENSIONAMENTO DE UN CAMPO DE SABER.
}

\section{Joseli Maria Silva}

Doutorado em Geografia pela Universidade Federal do Rio de Janeiro (UFRJ). Pòs-Doutaddo Complutense de Madrid e University of Brighton.

Av. General Carlos Cavalcanti, 4748 - Uvaranas, Ponta Grossa - PR, 84030-900, Brasil.

Email: joseli.genero@gmail.com

Tamires Regina Aguiar de Oliveira Cesar

Mestrado em Geografia (UEPG). Doutoranda em Geografia (UEPG).

Av. General Carlos Cavalcanti, 4748 - Uvaranas, Ponta Grossa - PR, 84030-900, Brasil.

Email: tamioliveiracesar@gmail.com

\section{Vagner André Morais Pinto}

Graduação em Geografia (UEPG). Mestrando em Geografia (UEPG).

Av. General Carlos Cavalcanti, 4748 - Uvaranas, Ponta Grossa - PR, 84030-900, Brasil.

Email:vampmorais@gmail.com

\section{RESUMO}

O artigo tem como objetivo analisar o tensionamento teórico que a abordagem de gênero provoca no campo conceitual já estabelecido, baseado na dicotomia entre o espaço público e o espaço privado. Para cumprir este objetivo tomamos por base duas pesquisas realizadas no âmbito do Grupo de Estudos Territoriais. Uma delas aborda inserção feminina marginal na produção do conhecimento geográfico brasileiro que tem por base 13.990 artigos referentes à exploração de 90 periódicos científicos classificados na área de geografia pelo Sistema Qualis-Capes do triênio 2013-2015. A outra pesquisa é de caráter qualitativo que investiga o uso do tempo cotidiano feminino e masculino de seis casais de pessoas envolvidas no mundo acadêmico, bem como as subjetivações que envolvem suas posições sociais de gênero e a respectiva produção científica. Como resultado do cruzamento dessas duas investigações podemos argumentar que a dicotomia entre espaço público e privado, fruto de uma visão masculina, moderna e eurocentrada de ciência obscurece a compreensão da importância do gênero no processo de produção científica na geografia brasileira.

PALAVRAS CHAVE: gênero, ciência geográfica, produção científica, epistemologia 


\begin{abstract}
The aim of this article is to analyze the theoretical tensioning that gender approach produces in the established conceptual field of Geography, which based on the public and private space dichotomy. To achieve this goal, we were based on two investigations developed in the Territorial Studies Group. One of them addresses the female marginal insertion in the Brazilian geographical knowledge production and investigates 13.990 articles from 90 scientific journals classified in geographic area by Qualis-Capes System in 2013-2015 triennium. The other one has a qualitative approach and explores the way men and women use their daily time. The research considered six couples involved in the academic world, as well their subjectivation regarding their gender position and their scientific production. As a result of crossing both investigations, we can argue that the public and private dichotomy of geographical space, originated in a male, Eurocentric and modern vision of science can obscure gender relevance in the Brazilian Geography scientific production.
\end{abstract}

KEYWORDS: gender, geographical science, scientific production, epistemology.

\title{
RESUMEN
}

El artículo tiene como objetivo analizar la tensión teórica que el enfoque de género provoca en un campo conceptual ya establecido, basado en la dicotomía entre el espacio público y el espacio privado. Para cumplir con este objetivo se toman como base dos investigaciones realizadas en el marco del Grupo de Estudios Territoriales. Una de ellas aborda la inserción femenina marginal en la producción del conocimiento geográfico brasileño que se basa en 13.990 artículos referentes a la exploración de 90 revistas científicas clasificadas en el área de geografía por el Sistema Qualis-Capes durante el trienio 2013-2015. La otra investigación es de carácter cualitativo e investiga el uso del tiempo cotidiano femenino y masculino de seis parejas de personas involucradas en el mundo académico, así como las subjetividades que implican sus posiciones sociales de género y su respectiva producción científica. Como resultado del cruce de estas dos investigaciones se puede argumentar que la dicotomía entre espacio público y privado, fruto de una visión masculina, moderna y eurocéntrica de la ciencia, obscurece la comprensión de la importancia del género en el proceso de la producción científica en la geografía brasileña.

PALABRAS-CLAVE: género, ciencia geográfica, producción científica, epistemología. 


\section{INTRODUÇÃO}

Apesar de já estar desenvolvendo pesquisa sobre gênero e geografia desde 2003, foi em 2006 que eu realizei minha primeira apresentação pública sobre a relação entre gênero e geografia no V Simpósio Nacional sobre Espaço e Cultura e o I Simpósio Internacional sobre Espaço e Cultura nas dependências da Universidade Estadual do Rio de Janeiro $(\text { UERJ })^{1}$. O evento foi realizado pelo Núcleo de Estudos e Pesquisas sobre Espaço e Cultura (NEPEC ), cujos coordenadores da época, Zeny Rosendahl e Roberto Lobato Corrêa, tinham simpatia pelo tema de gênero na geografia, facilitando, naquele momento, a enunciação de uma abordagem ainda marginal no Brasil em um fórum de discussão acadêmica.

Preparei toda minha argumentação em torno de geógrafas/os, a fim de evidenciar que o tema já tinha tradição epistemológica no campo da Geografia em outros países. Após o encerramento da mesa redonda, cujo título era "Novas perspectivas da Geografia Cultural", os ouvintes se manifestaram com perguntas e críticas às apresentações que haviam sido realizadas. O tema e a fala havia provocado os ânimos dos ouvintes. Eu resgato aqui uma das mais contundentes críticas, realizada por uma professora por quem nutro profundo respeito e admiração acadêmica. Seu argumento foi de que o gênero era uma abordagem da sociologia, da antropologia e da história, mas não cabia à Geografia. Não cabia à geografia porque esta já tinha um objeto estudo, o espaço, o qual constituía sua identidade científica. Alegou ainda que os conceitos geográficos, que sustentam o campo disciplinar não implicavam a compreensão de gênero.

Um tanto tensa em responder à crítica da referida professora, dado que reconhecia e legitimava a hierarquia das posições acadêmicas e sabia que ela estava em um patamar muito superior ao meu, lhe respondi com questionamentos. Eu sou uma mulher e meu corpo possui forma, tamanho e desempenha ações. Por acaso sou eu um ser não espacial? Ou há um problema com a ciência geográfica brasileira que tem se mostrado incapaz de constituir uma compreensão da minha realidade espacial como mulher? Possivelmente não tenha convencido ninguém sobre a importância do gênero na ciência geográfica naquele momento. Afinal, as palavras são legitimadas quando as pessoas reconhecem o poder de quem as profere e, certamente eu sabia de minha desvantagem em termos de reconhecimento acadêmico.

Desde então, passei a desenvolver um olhar especial sobre a forma como o conhecimento é produzido e as tensões que novas proposições provocam nas relações de poder que organizam o campo científico. Esta reflexão parte de uma experiência pessoal que foi

${ }^{1}$ Relato de experiência Joseli Maria Silva. 
sendo enriquecida por debates realizados no âmbito do Grupo de Estudos Territoriais ${ }^{2}$. Ideias de outros pesquisadores foram sendo agregadas e nesse sentido, tais pessoas acabaram se constituindo em coautores deste texto ${ }^{3}$.

Nosso objetivo é realizar uma análise sobre o tensionamento teórico que a abordagem de gênero provoca no campo conceitual já estabelecido, tomando como base a dicotomia entre o espaço público e o espaço privado. Para alcançar o propósito estabelecido utilizamos duas pesquisas desenvolvidas no Grupo de Estudos Territoriais da Universidade Estadual de Ponta Grossa - GETE/UEPG . Uma delas analisou a produção acadêmica feminina e masculina a partir de 13.990 artigos científicos publicados no período 1974 a $2013 \mathrm{em}$ 90 periódicos científico que constam na listagem da área de geografia por meio do Sistema Qualis-CAPES ${ }^{4}$, correspondente ao triênio 2013-2015. A outra pesquisa considerou o uso do tempo cotidiano de seis casais heterossexuais que fazem parte do mundo científico, bem como a realização de entrevistas em profundidade para compreender a rede semântica que possibilita a compreensão das subjetivações dos sujeitos em diferentes posições de gênero.

Na primeira parte do texto estabelecemos uma discussão sobre a necessidade fundamental de se construir nas Geografias Feministas um contra discurso epistemológico, capaz de produzir visibilidade às problemáticas que envolvem o gênero e espaço. Na segunda seção analisamos os tensionamentos teóricos provocados sobre os conceitos já estabelecidos pelas pesquisas sobre gênero e produção acadêmica na Geografia Brasileira , destacando o potencial enriquecedor da vertente feminista à ciência geográfica.

\section{UMA CIÊNCIA REBELDE PARA DESCONSTRUIR INVISIBILIDADES HIS- TORICAMENTE PRODUZIDAS PELA METANARRATIVA DA HISTÓRIA DO PENSAMENTO GEOGRÁFICO.}

O texto de Barnett (1995) 'Despertando os mortos: quem precisa da história da geografia?' estabelece uma crítica sobre a forma como as comunidades geográficas contam e registram sua própria história, a fim de perpetuar hegemonias e constituir uma aura de verdade absoluta dos acontecimentos científicos. As narrativas historiográficas da ciência se perpetuam pelos currículos acadêmicos que são repetidamente populados por personagens históricos heroicos de determinados períodos e localidades. As narrativas históricas são internalizadas e reproduzidas incessantemente, até que, por força da tradição ritualística, a verdade inquestionável se estabeleça.

\footnotetext{
${ }^{2}$ O Grupo de Estudos Territoriais (GETE) desenvolve pesquisas relacionadas às discussões de gênero e sexualidades na ciência geográfica. ${ }^{3} \mathrm{~A}$ linguagem é um ato político. Utilizo a primeira pessoa do singular e do plural por reconhecer que os autores ocupam lugares geopolíticos na construção do saber e são epistemologicamente e socialmente situados.

${ }^{4}$ Coordenação de Aperfeiçoamento de Pessoal de Nível Superior (CAPES)
} 
O geógrafo David Bell (2011) em seu texto: 'O que foi, terá sido? A geografia a partir do queer' traz uma interessante reflexão em torno do desenvolvimento da historiografia das geografias das sexualidades, que pode servir de base de compreensão para a historiografia da geografia como um todo. Para ele, mais importante do que interiorizar a narrativa histórica de desenvolvimento da geografia, é observar como ela é contada, narrada e entender como esta narrativa produz discursos próprios. Segundo Bell (2011), as histórias dominantes são mantidas pela reprodução dessa metanarrativa em nossas próprias publicações em forma de artigos científicos, livros e em nossa prática pedagógica em sala de aula. Mesmo sabendo da alta complexidade que envolve as disputas conceituais em um determinado campo científico, acabamos por ser cúmplices rotineiros da simplificação de nossa história científica. David Bell não está interessado em corrigir distorções do passado científico, mas em analisar os mecanismos de funcionamento das narrativas historiográficas e de como a forma como contamos nosso passado científico faz com que estejamos também construindo o presente e o futuro da ciência.

Ao analisar o conteúdo das ementas das disciplinas que envolvem a discussão de 'Epistemologia da Geografia' nos cursos de Pós-graduação em Geografia em universidades brasileiras é comum a ausência das chamadas Geografias Feministas, apesar de ela ser quase tão antiga quanto a vertente crítica da Geografia (Gibbons, 2001). Além disso, nas indicações bibliográficas são escassas as indicações de obras femininas, com raras exceções. Os nomes femininos mais comuns encontrados nos programas das disciplinas foram os de Anne Buttimer e Doreen Massey.

Bell (2011) compartilha sua experiência científica e didática em torno da historiografia da geografia dizendo

\footnotetext{
Já há alguns anos eu tenho trabalhado arduamente com esta narrativa, ministrando em curso sobre histórias, filosofias e teorias da geografia humana. Esta história é muitas vezes contada de maneira terrivelmente ordenada, com muita reorganização retrospectiva e edição. Mas há também um superávit para o que nós poderíamos chamar de 'história honesta da geografia', onde aparecem as interrupções, os retornos dos reprimidos, os fantasmas. Uma forma pela qual estas histórias se materializam é através de histórias pessoais, considerações que adicionam detalhes complicados, que promovem o debate, que nos mostram os truques que nossas memórias nos pregam. (BELL, 2011, p. 202-203)
}

As ênfases de determinados personagens na metanarrativa, constantemente reproduzida na prática científica e pedagógica cotidiana, reforça a difusão e a legitimação de conceitos e formas de interpretação da realidade, criando hegemonias e privilégios epistêmicos, como argumenta Mignolo (2003 a) e Lander (2005). 
Trazer para arena do debate científico geográfico os saberes produzidos pelos 'condenados da ciência'5 (mulheres, negros, homossexuais) de forma emancipatória, significa instituir uma razão decolonial ${ }^{6}$ do saber científico e das práticas cotidianas que o sustentam.

Aníbal Quiano (2000) argumenta que o saber científico, tal como o conhecemos, é, ainda hoje um instrumento imperial da colonização. Ele afirma que embora o colonialismo seja um processo histórico acabado, isso não significou o fim da colonialidade. A colonialidade do saber compõe formas de organização do mundo que permanecem arraigadas na racionalidade da sociedade contemporânea. A ideia da colonialidade do poder, formulada pelo referido autor, considera que a matriz colonial de poder é uma estrutura complexa de eixos entrelaçados que envolve o controle da economia, da autoridade, do poder, da natureza, do gênero, da sexualidade, da subjetividade e do conhecimento. Assim, a colonialidade se reproduz em uma tripla dimensão: a do poder, a do saber e a do ser.

A colonialidade é o lado obscuro e indissociável da modernidade ${ }^{7}$, como argumenta Mignolo (2003b). A colonialidade do saber não é algo que atinja apenas o mundo colonial ou que diga respeito apenas aos excluídos do privilégio de enunciação do saber. Ao contrário, a racionalidade da colonialidade é onipresente, afetando a manutenção de mecanismos que dificultam a criação de novas formas de constituir relações entre saberes a partir da ideia da multiplicidade de conhecimentos e da plurilocalidade de saberes.

A simples inclusão das mulheres, negros e homossexuais na produção do saber científico não basta para transformarmos a lógica da hegemonia. Isso porque a inclusão pode ser perversa e significar uma nova forma de assimilação da cultura científica hegemônica moderna. Paul Cloke e Ron Johnston (2005) argumentam que a modernidade criou a ideia binária de compreensão do mundo, gerando hierarquias entre natureza/cultura, homem/mulher, razão/emoção, público/privado e assim por diante. Acima de tudo, a modernidade criou o referente universal do saber científico branco, masculino, heterossexual.

O binarismo não é uma característica inocente da ciência geográfica, mas forte instrumento de dominação e de manutenção de sujeitos hegemônicos. O espaço urbano, tradicionalmente estudado na geografia brasileira traz as ruas, praças, parques, bairros e assim por diante como elementos corriqueiros do espaço urbano. A análise da cidade é in-

\footnotetext{
${ }^{5}$ Fazemos uma analogia com 'Os condenados da terra', de Fanon (1968).

${ }^{6} \mathrm{O}$ termo 'decolonial' é utilizado no sentido de marcar um posicionamento e uma atitude contínua de transgredir e insurgir, trazendo a ideia de uma luta contínua para identificar e visibilizar construções alternativas à colonialidade do poder e do saber. ${ }^{7}$ Enquanto a Europa conheceu o lado da modernidade o mundo conquistado conheceu a modernidade ao avesso, a colonização. Assim, nos alinhamos a ideia de Walsh (2012) que diz que a modernidade não começa com o iluminismo nos séculos XVII e XVIII, mas muito antes, com os vínculos formados entre a racionalidade formal, a aspiração de dominar o mundo e a emergência de um mercado mundial. São esses vínculos que dão base para a noção do progresso linear, da superioridade do homem branco europeu sobre a natureza e o capitalismo como um marco único para orientar e controlar o pensamento e a vida.
} 
terrompida quando se trata da casa e seu interior. O privilégio ao espaço público como interesse geográfico impossibilitou a visibilidade de relações que se tornam compreensíveis quando a dicotomia entre espaço público e privado é superada. (PRZYBYSZ, 2011).

A produção conceitual que constitui um campo de estudo cria os parâmetros pelos quais a realidade é interpretada e comunicada no cotidiano do fazer científico. A cidade não é 'naturalmente' dicotomizada entre espaço público e privado. Esta forma de compreender o espaço urbano é uma criação do campo científico que se perpetua, até que se estabeleça como verdade inquestionável. O conceito, através do qual cientistas interpretam a realidade é tomado por si, sem ao menos haver o questionamento da genealogia dessa forma interpretativa da realidade. A repetição institui a tradição epistêmica que cria resistências às diferentes formas de olhar a realidade espacial, como é o caso das relações de gênero na geografia brasileira.

Assim, queremos afirmar que é a forma como os conceitos geográficos foram concebidos que impossibilita a visibilidade da espacialidade feminina ${ }^{8}$ e, nesse sentido, é o campo científico que deve ser tensionado para que, parafraseando David Bell (2011), haja o 'retornos dos reprimidos, os fantasmas' como sujeitos legítimos do fazer geográfico cotidiano.

As mulheres fazem parte da produção do conhecimento geográfico e a partir da dicotomia entre o espaço público e privado, com ênfase no primeio, impera a ideia de que o mundo acadêmico atual já eliminou as possíveis iniquidades de gênero. É comum cientistas negarem a iniquidade de gênero no processo de produção científica, inclusive, para nosso pesar, por parte de várias mulheres que fazem parte do mundo acadêmico.

As alegações para justificar a equidade de gênero na produção científica baseiam-se nos seguintes argumentos: homens e mulheres estão submetidos à mesma carreira docente, recebem salários iguais, trabalham nas mesmas instalações, estão sujeitos às mesmas exigências de produtividade e carga-horária de trabalho. O recorte da produção científica baseado apenas no espaço universitário esconde parte do mecanismo de gênero que diferencia as condições do trabalho acadêmico entre homens e mulheres, criando assim uma pretensa equidade de condições de produção científica.

\section{PRODUZINDO A VISIBILIDADE DO GÊNERO COMO ELEMENTO DA PRODUÇÃO CIENTÍFICA GEOGRÁFICA.}

Os argumentos de equidade das condições de produção científica entre homens e mulheres, como dito no final da primeira seção, estão baseados na concepção dicotômica do

${ }^{8} \mathrm{Tal}$ invisibilidade não se restringe à sujeitos femininos, mas muitos outros grupos como grupos racializados e de sexualidades dissidentes da heterossexualidade. 
espaço, produzida a partir da modernidade. Ali Madanipour (2003) argumenta que o desafio em ultrapassar a dicotomia entre o público e o privado é fundamental para a luta feminina, já que a dicotomia obscurece a supremacia dos homens sobre as mulheres, gerando uma aparência universal igualitária entre ambos. Madanipour (2003) diz ainda que o problema que isto coloca é que o espaço público tem sido conceituado e discutido como sendo separado do espaço privado e este último acaba sendo negligenciado. Afirma sobretudo que 'o público e o privado' são inter-relacionados e, no mundo do trabalho, eles não podem ser entendidos como separados, sendo que um compõe o outro.

A visibilidade de fenômenos que envolvem o feminino provoca tensionamento na tradição epistemológica moderna e dicotômica. Reconhecendo que é preciso desafiar perspectivas científicas de interpretação da realidade socioespacial para que se evidencie as formas de organização dos espaços produzidos pelas mulheres, desenvolvemos alguns trabalhos que servem de base para o presente artigo.

Nossa argumentação está baseada em duas investigações desenvolvidas no âmbito do Grupo de Estudos Territoriais, cujos resultados servem de sustentação para a análise sobre o necessário tensionamento da tradição epistemológica na interpretação de fenômenos que envolvem sujeitos tradicionalmente invisibilizados no campo da Geografia brasileira.

Vejamos os resultados da primeira pesquisa que tinha como questão central a compreensão da posição das mulheres na produção científica da geografia brasileira. Foram considerados 90 periódicos ${ }^{2}$ disponíveis on-line, contabilizando 13.990 artigos científicos, considerando um período de 1974 a 2013. A análise considerou a classificação dos periódicos científicos em todos os estratos do Sistema Qualis-CAPES (A1, A2, B1, B2, B3, B4, B5) do triênio de avaliação 2013 - 2015. Tal sistema de avaliação de periódicos científicos cria um processo de hierarquização que distribui prestígio acadêmico nos estratos superiores e, nesse sentido, ele é um importante parâmetro de conquista de poder no camU $\underset{\substack{x \\ 0}}{\times}$ po científico ${ }^{\underline{10}}$.

A tabela a seguir evidencia a distribuição de autorias, considerando a classificação dos periódicos brasileiros da área da Geografia.

\footnotetext{
${ }^{9}$ A lista de periódicos presentes do Sistema Qualis - CAPES da área de geografia do triênio 2013-2015 contava com 102 periódicos. Entretanto, só foram considerados aqueles disponíveis na internet, ou seja 90 periódicos.

${ }^{10}$ Este texto não tem por objetivo discutir o processo de classificação dos periódicos científicos e a capacidade do instrumento classificatório usado plea CAPES em medir a qualidade da produção científica. Apenas queremos apontar que este indicador é um importante parâmetro de distribuição de poder entre pesquisadores de determinada comunidade científica.
} 
Tabela 1- Autoria, sexo e distribuição de artigos publicados em periódicos classificados pelo Sistema Qualis-CAPES - Triênio 2013-2015.

\begin{tabular}{l|c|c|c|c|c|c|c|c}
$\begin{array}{c}\text { Autores por estrato de } \\
\text { classificação Sistema } \\
\text { Qualis-CAPES }\end{array}$ & A1 & A2 & B1 & B2 & B3 & B4 & B5 & Total \\
Homens & 528 & 1741 & 2078 & 1918 & 980 & 1026 & 142 & 8413 \\
\hline Mulheres & 232 & 1042 & 1332 & 1437 & 716 & 728 & 90 & 5577 \\
\hline Total & 760 & 2783 & 3410 & 3355 & 1696 & 1754 & 232 & 13990 \\
\hline
\end{tabular}

Fonte: 90 periódicos científicos classificados pelos Sistema Qualis-CAPES, triênio 2013-2015.

A Figura 1 evidencia a distribuição da produção científica entre homens e mulheres, sendo que os homens possuem maior produção científica em todos os estatos de qualificação dos periódicos.

Figura 1 - Distribuição da Produção Científica Geográfica entre Homens e Mulheres a partir de Periódicos Científicos Classificados no Sistema Qualis-CAPES- Área de Geografia.

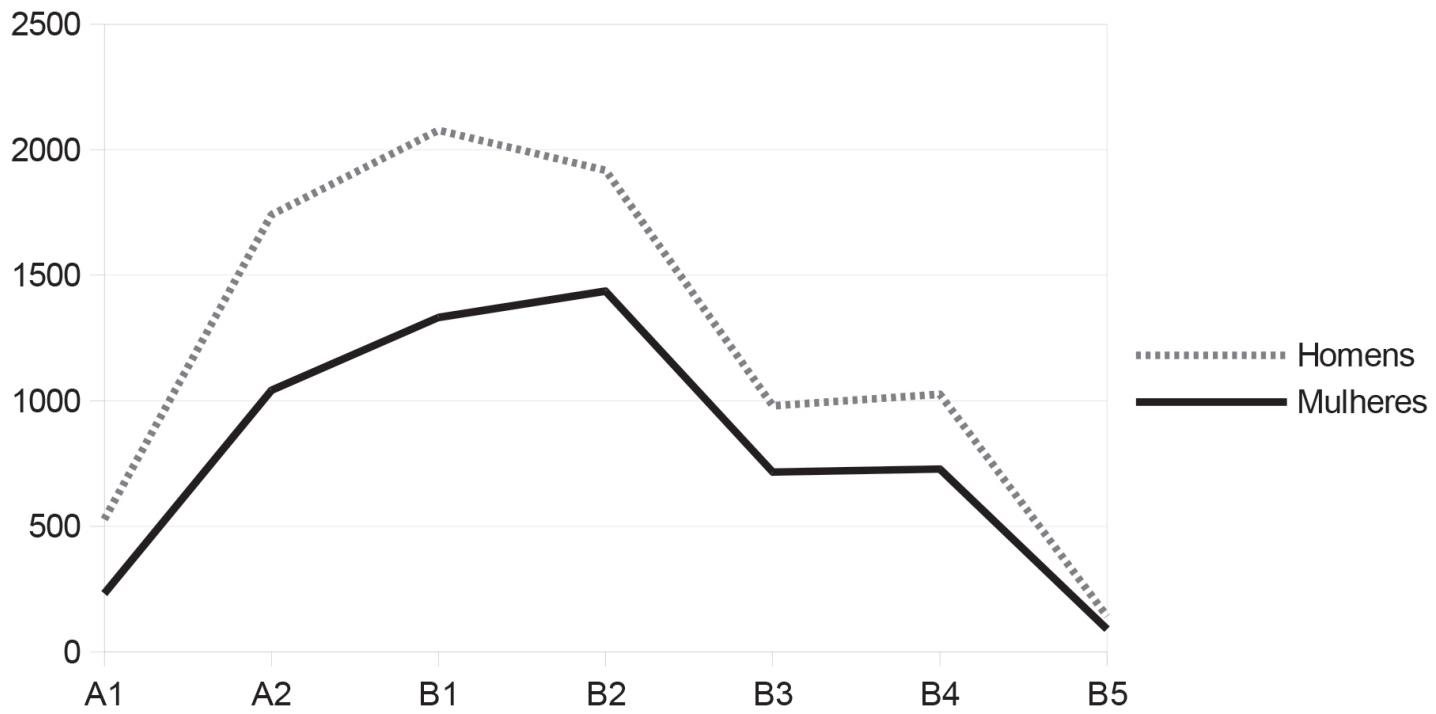

Org: CESAR, Tamires Regina Aguiar de Oliveira

Fonte: 90 periódicos científicos on-line classificados no Sistema Qualis-CAPES, triênio 2013-2015, área da Geografia.

Além dos homens se destacarem em todos os estratos, há ainda um agravante. O conjunto dos homens pesquisadores na área da Geografia conseguem publicar com mais intensidade nos veículos acadêmicos de maior qualificação, conforme a CAPES. A Figura 2 evidencia esse argumento. 
Figura 2 - Participação de homens e mulheres na autoria de artigos científicos publicados em periódicos classificados por estrato segundo Sistema Qualis-CAPES- Área de Geografia.

$30,0 \%$

$25,0 \%$

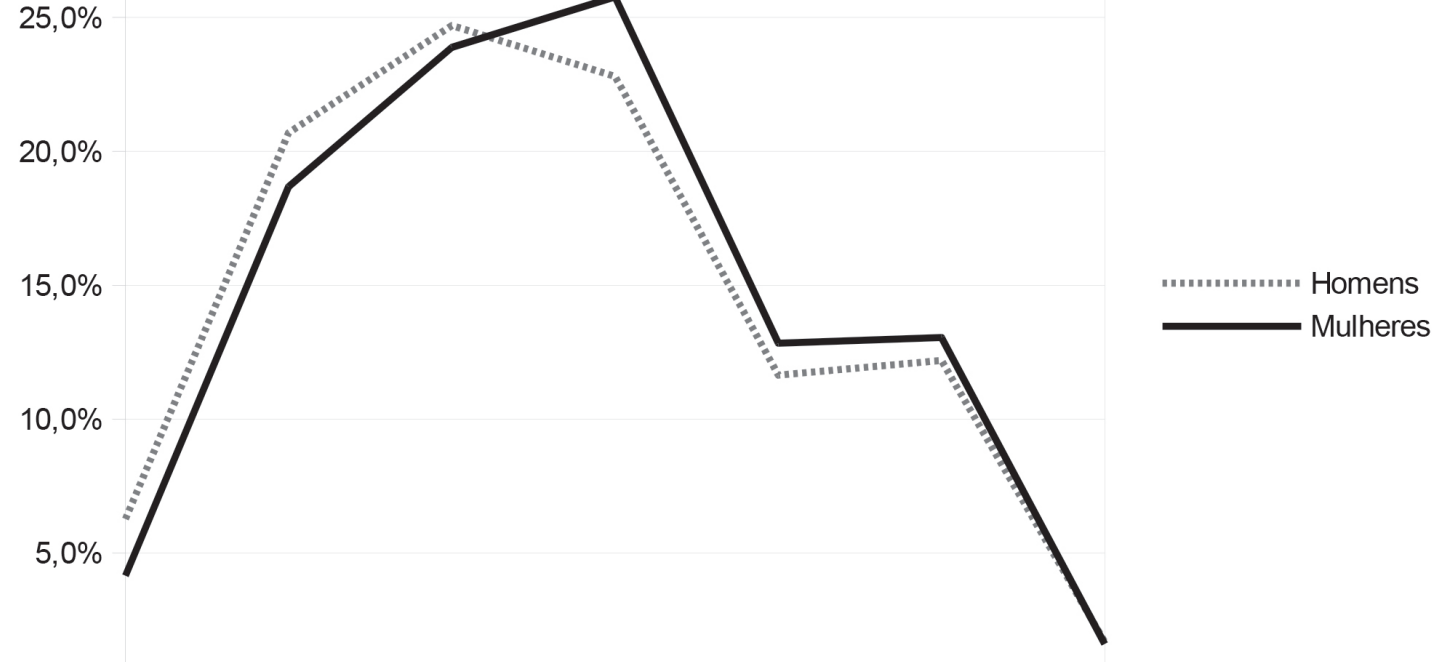

$0,0 \%$
A1
A2
B1
B2
B3
B4
B5

Org: CESAR, Tamires Regina Aguiar de Oliveira

Fonte: 90 periódicos científicos on-line classificados no Sistema Qualis-CAPES, triênio 2013-2015, área da Geografia.

Os estratos considerados melhor qualificados pelo Sistema-Qualis são, portanto, majoritariamente masculinos, enquanto que as mulheres conquistam maior expressão nos periódicos classificados nos estratos inferiores. Além disso, a supremacia masculina também marca os conselhos editoriais dos periódicos científicos analisados. Fazer parte de conselhos editoriais, significa conquistar uma posição de prestígio e privilégio, já que é este o grupo que faz parte da arbitragem da produção científica e pode decidir aquilo que vai ou não ser aceito para publicação, possibilitando, assim a marca do cientista na historiografia do campo de saber. A Figura 3 evidencia que a diferença entre homens e mulheres se mantêm de forma expressiva em todos os estratos. Impressionante é a quase total inexistência feminina em conselhos editoriais de periódicos considerados no estrato A1 e não é surpresa observar que a menor diferença entre homens e mulheres é no estrato B5. 
Figura 3- Distribuição da Proporção entre Homens e Mulheres como membros de Conselhos Editoriais/ Científicos de Periódicos Científicos Classificados no Sistema Qualis-CAPES- Área de Geografia.

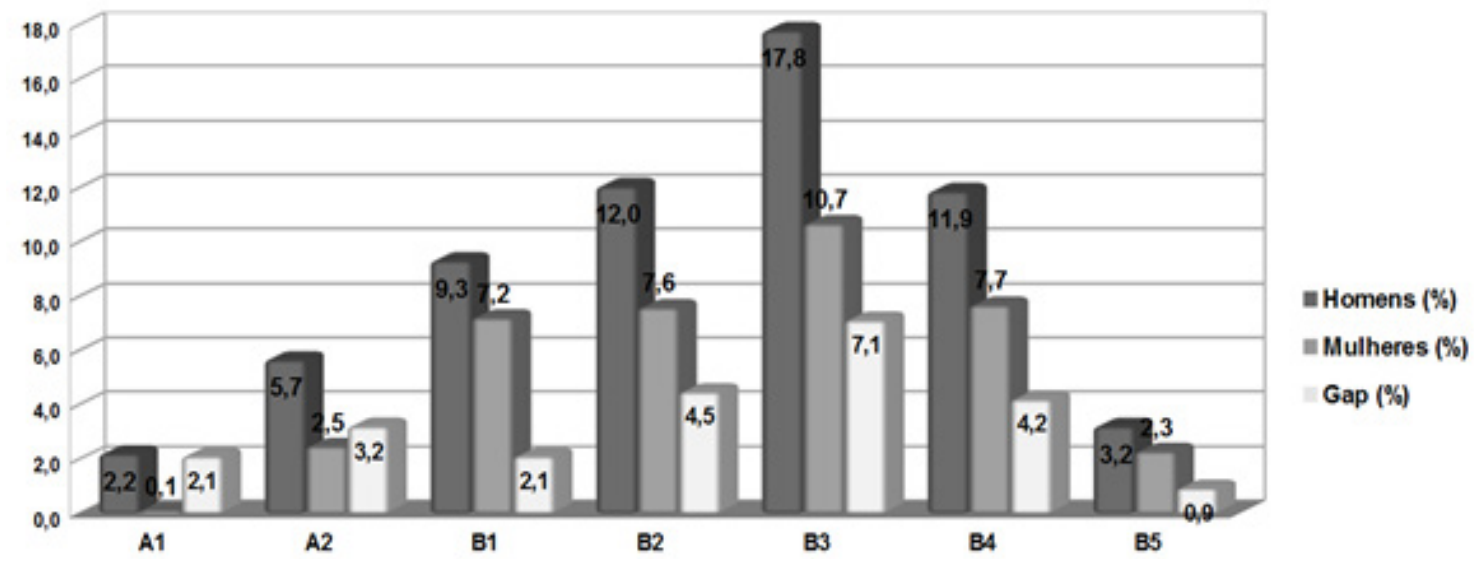

Org: CESAR, Tamires Regina Aguiar de Oliveira

Fonte: 90 periódicos científicos on-line classificados no Sistema Qualis-CAPES, triênio 2013-2015, área da Geografia.

Esta pesquisa nos permite afirmar que a produção científica feminina na área da geografia está posicionada em periódicos com menor prestígio acadêmico, conforme os critérios de avaliação da CAPES. A intensificação das exigências de aumento de produtividade científica por parte dos docentes tem sido cada vez maior à partir dos anos 90, sendo gradativamente fortalecida. As reflexões de Cruz (2012) apontam que este processo de avaliação da qualidade que é medida pela produção de artigos científicos produzidos pelos docentes, tem gerado uma pressão sobre a atividade laboral de pessoas envolvidas na pesquisa, tendo como foco o aumento da produtividade científica. A autora ainda ressalta que há uma exigência em ser um profissional qualificado e ao mesmo tempo manter o equilíbrio no trabalho, na produtividade científica acadêmica e na vida pessoal.

A jornada de desempenho de atividades laborais dos docentes, notadamente a produção de artigos científicos, tem sido realizada fora do espaço da universidade, na maior parte das vezes, no espaço doméstico. Neste ponto de nossa argumentação se coloca um primeiro tensionamento da tradição dicotômica entre o público e o privado em que é nítida a permeabilidade entre ambos os espaços. Entretanto, a especificidade do espaço privado traz de forma mais contundente as relações de dominação de gênero que influenciam na forma como homens e mulheres usam seu tempo.

Para melhor discutir este ponto vejamos outra pesquisa realizada no âmbito do Grupo de Estudos Territoriais, cuja questão central é compreender como o exercício dos papéis masculinos e femininos influenciam na organização do tempo na produção científica de artigos acadêmicos. Assim, para dar conta dessa questão, utilizamos a metodologia 
de análise do uso do tempo criada pelo Instituto Brasileiro de Geografia e Estatística (IBGE). Foram aplicados questionários minuciosos acerca da rotina em dias letivos e não letivos, junto a 12 pessoas que compõem 6 (seis) casais heterossexuais de professores pesquisadores de diversas áreas do conhecimento e sob regime de dedicação exclusiva da Universidade Estadual de Ponta Grossa. Considerando os casais em conjunto, as idades oscilam de 39 até 52 anos. Apenas um casal não possui filhos (as), três casais possuem um filho cada e dois casais possuem dois filhos(as) cada.

Os dados preenchidos nas planilhas de uso do tempo cotidiano foram reunidas em cinco categorias. 1- atividade produtiva docente, que compreende o tempo gasto com pesquisa, docência e extensão; 2 - lazer, onde foram consideradas as atividades de atividades de entretenimento e passeios; 3 - cuidado pessoal, onde foram computadas as atividades de higiene pessoal, alimentação e prática de exercícios físicos; 4- reprodução familiar, onde foram reunidas as horas gastas com a realização de atividades de limpeza e organização da casa, preparo de refeições e cuidado de outros membros da família; 5- ócio, onde foram reunidas as horas gastas para repouso. A Figura 4 evidencia as diferenças entre homens e mulheres no que diz respeito ao uso do tempo durante os dias de semana.

\section{Figura 4: Distribuição do Uso do Tempo de Homens e Mulheres entre Segunda e Sexta feiras contabilizado por hora.}

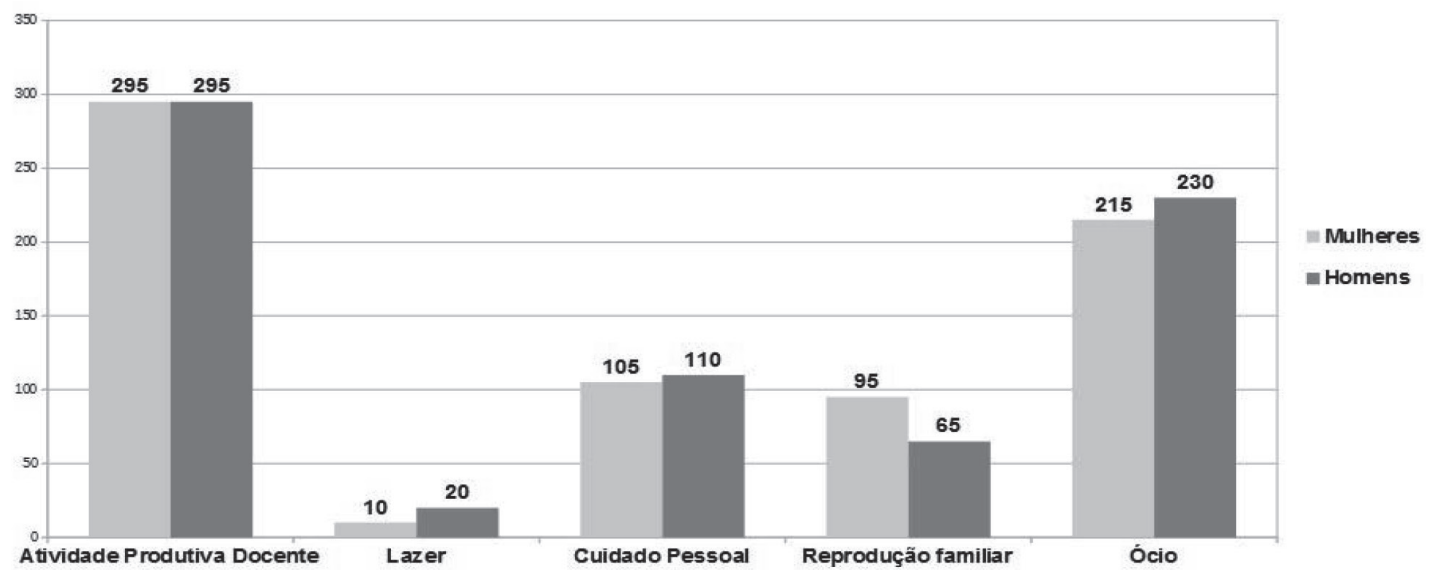

Org: PINTO, Vagner A.M.

Fonte: Questionários de uso do tempo realizados com 12 pessoas que formam 6 casais heterossexuais da UEPG em 2014.

Nos dias de semana homens e mulheres dedicam a mesma quantidade de tempo às atividades de docência, pesquisa e extensão. Contudo, mulheres dedicam mais tempo que homens na reprodução familiar. Este tempo é retirado do lazer, cuidado pessoal e ócio por 
parte da mulheres. As atividades domésticas são consideradas trabalho e, sendo assim, há um excedente de horas de trabalho feminino em relação ao masculino ${ }^{11}$.

Na Figura 5 a seguir é possível observar que as atividades docentes adentram os finais de semana de homens e mulheres, mas os homens possuem mais horas de dedicação nessa categoria. Já as mulheres, mais uma vez, possuem menos tempo dedicado ao cuidado pessoal, ao ócio e ao lazer e concentram seu tempo em atividades de reprodução familiar. Enquanto o trabalho docente nos dias de semana é realizado em tempo equilibrado de dedicação de ambos, nos finais de semana as mulheres retiram tempo de produção acadêmica e investem nas atividades de reprodução familiar.

\section{Figura 5: Distribuição do Uso do Tempo de Homens e Mulheres entre Sábado e Domingo contabilizado por hora.}

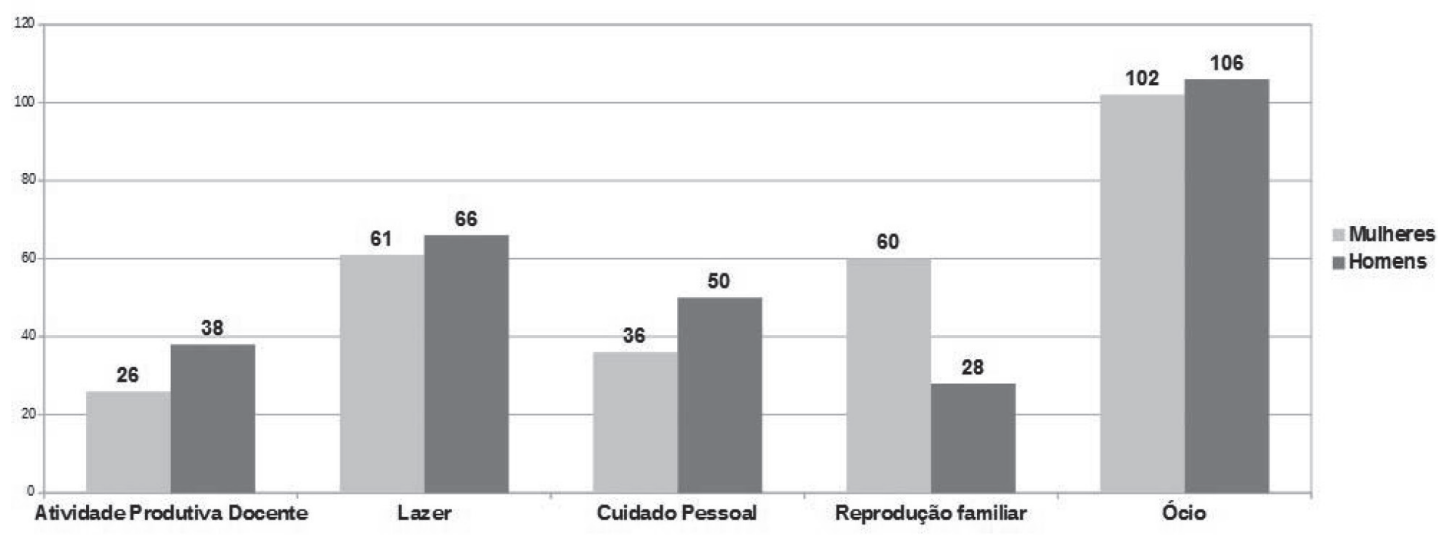

Org: PINTO, Vagner A.M.

Fonte: Questionários de uso do tempo realizados com 12 pessoas que formam 6 casais heterossexuais da UEPG em 2014.

O elemento que agrava a distribuição de tarefas entre homens e mulheres é o nascimento dos filhos. A Figura 6 a seguir evidencia que os casais com a presença de filhos apresentam uma forma mais desequilibrada de distribuição de uso do tempo entre homens e mulheres. Os filhos, embora sejam do casal, trazem consequências de maior restrição ao desempenho acadêmico às mulheres.

\footnotetext{
${ }^{11} \mathrm{O}$ dados nacionais confirmam nossa exploração. A Fundação Perceu Abramo em 2010 realizou uma pesquisa sobre o uso do tempo de homens e mulheres em tarefas de reprodução familiar com 2365 mulheres e 1181 homens em 280 município em 25 Unidades da Federação e a conclusão a que esta pesquisa chegou é a de que as mulheres brasileiras gastam $29 \mathrm{~h} 21$ ' por semana em atividades de reprodução familiar, enquanto os homens gastam apenas 8 h46'.
} 


\section{Figura 6: Distribuição do Uso do Tempo (por hora) de Homens e Mulheres, conforme situação de parentalidade.}

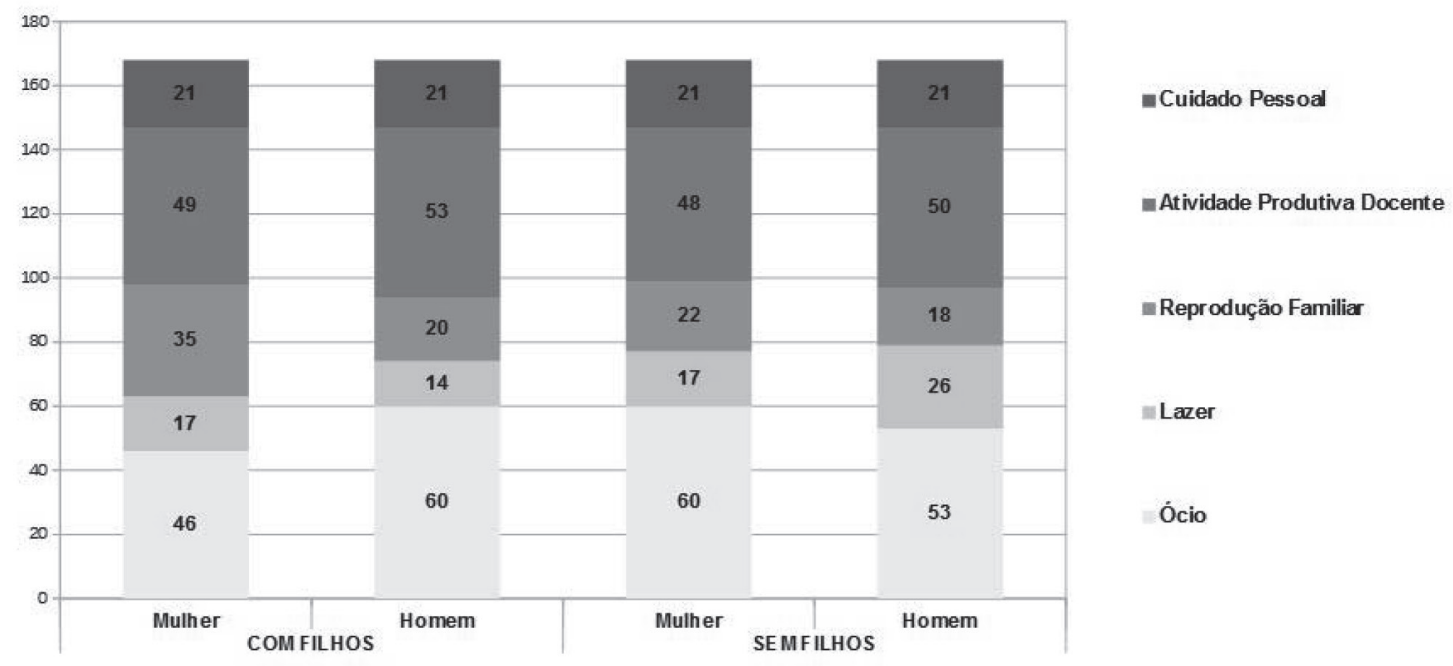

Org: PINTO, Vagner A.M.

Fonte: Questionários de uso do tempo realizados com 12 pessoas que formam 6 casais heterossexuais da UEPG em 2014.

As exigências atuais de aumento de produtividade acadêmica têm exigido de homens e mulheres docentes a extensão da jornada de trabalho, executada para além do espaço universitário, no espaço doméstico privado, segundo as análises de Borsoi (2012). Considerando os dados de uso do tempo evidenciados nos gráficos 4, 5 e 6, é possível afirmar que pelo fato das mulheres dedicarem mais tempo do que os homens desempenhando o trabalho de reprodução familiar, há uma tendência de estabelecimento de conflitos entre as demandas da carreira científica e as exigências do cuidado familiar.

Os dados da pesquisa realizada por Borsoi e Pereira (2011) evidenciam que o padrão de gênero que institui as mulheres como as principais responsáveis pelas tarefas de reprodução familiar, associado ao fato de que há uma pressão ao aumento da produtividade científica na carreira docente universitária resulta em um maior impacto na saúde das mulheres pesquisadoras do que na dos homens. Segundo Borsoi e Pereira (2011, p. 120) "as mulheres declaram jornadas de trabalho mais extensas, usam medicação prescrita com maior frequência e apresentam mais sintomas de sofrimento ou adoecimento.”

A análise da produção científica masculina e feminina baseada apenas na visibilidade do espaço universitário, ignorando o espaço privado, pode trazer conclusões equivocadas sobre a produção das mulheres na Geografia e a manutenção da falsa ideia de equidade de gênero no âmbito acadêmico. Afinal, se homens e mulheres possuem as mesmas con- 
dições laborais, cumprem a mesma jornada de trabalho formal, estão submetidos ao mesmo plano de carreira, usufruem as mesmas instalações laboratoriais e assim por diante e, mesmo assim, os homens conseguem divulgar sua produção científica em periódicos melhor classificados, são os homens 'mais aptos' a carreira acadêmica? Logicamente ninguém responderia positivamente à esta questão em pleno século XXI, depois de tantas conquistas feministas. Contudo, a visão dicotômica entre os espaços público e o privado concebe modelos de interpretação da realidade socioespacial que produz privilégio masculino e ainda obscurece grande parte dos mecanismos capazes de visibilizar a realidade feminina.

Apenas com o rompimento da dicotomia dos espaços público e privado, conforme Madanipour (2003) e Przybysz (2011), é possível compreender que há um imenso universo, por muitos anos considerados como 'tema não geográfico de investigação', capaz de trazer elementos que tornem visível os processos de opressão e dominação no mundo de produção científica.

\section{CONSIDERAÇÕES FINAIS}

Este artigo teve como fio condutor analisar o tensionamento teórico que a abordagem de gênero provoca no campo conceitual já estabelecido, baseado na dicotomia entre o espaço público e o espaço privado. Para sustentar nossas argumentações trouxemos duas pesquisas realizadas no âmbito do Grupo de Estudos Territoriais que foram analisadas de forma relacional, evidenciando a ideia de continuidade e inter-relação entre os espaços público e privados. A naturalização das dicotomias e o seu registro histórico no campo científico se estabelece pelas metanarrativas que são culturalmente estabelecidas na comunidade geográfica. A naturalização dos pressupostos conceituais instituem uma ritualização acadêmica que torna o campo conceitual cristalizado, dificultando a visibilidade de grupos sociais. Tal visibilidade só ocorre quando assumimos que a ciência deve ser vivida de forma rebelde, tensionando o campo conceitual preestabelecido.

Retomando as experiências sobre as primeiras discussões públicas sobre gênero e geografia relatadas na introdução desse trabalho, podemos, com segurança fazer nosso pronunciamento no campo científico geográfico brasileiro de que o gênero não fez parte da análise geográfica pelo apego à tradição epistemológica e não pelo fato de que mulheres não sejam seres espaciais. 


\section{REFERÊNCIAS}

1. BARNETT, Clive. Awakening the dead: who needs the history of geography? Transactions of the Institute of British Geographers, v. 20, n. 4, p. 417-419, 1995

2. BELL, David. O que foi terá sido: A Geografia a partir do queer. In: SILVA, J. M.; SILVA, A. C. P. da. Espaço, gênero e poder: conectando fronteiras. Ponta Grossa: Todapalavra, 2011, p. 201-214.

3. BORSOI, Izabel Cristina Ferreira. Trabalho e produtivismo: saúde e modo de vida de docentes de instituições públicas de Ensino Superior. Cadernos de Psicologia Social do Trabalho. v.. 15, n. 1, p. 81-100, 2012.

4. BORSOI, Izabel Cristina Ferreira e Flavilio Silva Pereira. Mulheres e homens em jornadas sem limites: docência, gênero e sofrimento. Temporalisa. v. 11, n. 21, p.119-145, jan./jun. 2011.

5. CLOKE, Paul J. \& JOHNSTON, Ron. J. Spaces of Geographical Thought: Desconstructing Human Geography’s Binaries. London: Sage Publications, 2005.

6. CRUZ, Rita de Cássia Ariza. "Se a CAPES somos nós, quem somos nós? A pós- graduação brasileira em busca de uma identidade”. Grupo de Geografia Urbana Crítica Radical (USP), s/n, p 1-13, abril 2012.

7. FANON, Frantz. Os Condenados da Terra. Lisboa: Ulmeiro, 1968.

8. GIBBONS, Wendy. 'Critical of What?': Past and Current Issues in Critical Human Geography”. History of Intellectual Culture, v. 1, n. 1, 2001, p. 1-16.

9. LANDER, Edgardo. Ciências Sociais: saberes coloniais eurocêntricos. In: A Colonialidade do Saber: eurocentrismo e ciências sociais perspectivas latino-americanas. Buenos Aires, Argentina, Colección Sur Sur, 2005. p. 8-23.

10. MADANIPOUR, Ali. Public and private spaces of the city. London: Routledge, 2003.

11. MIGNOLO, Walter. "Os esplendores e as misérias da 'ciência': Colonialidade, geopolítica do conhecimento e pluri-versalidade epistémica”. In: SOUSA SANTOS, Boaventura. Conhecimento prudente para uma vida decente: Um discurso sobre as ciências revistado. Porto: Edições Afrontamento, 2003a, p. 667-709.

12. MIGNOLO, Walter. "Second Thoughts on The Darker Side of the Renaissance: Afterword to the second edition". In: MIGNOLO, Walter. Darker Side of the Renaissance: Literacy, Territoriality and Colonization. Ann Arbor: The University of Michigan Press, 2003b, p. 428-433.

13. QUIJANO, Anibal. "Coloniality of Power, Eurocentrism and Latin America”. Neplanta: Views from South. v. 1, n. 3, p. $533-580,2000$.

14. PRZYBYSZ, Juliana. Articulando os espaços público e privado: transformações das espacialidades vividas por mulheres responsáveis pelo domicílio, após a dissolução conjugal na cidade de Ponta Grossa - Paraná. 2011. 184 f. Dissertação (Mestrado em Gestão do Território) - Universidade Estadual de Ponta Grossa, Ponta Grossa. 2011

15. WALSH, Catherine. "Interculturalidad, plurinacionalidad y razón decolonial: refundares político-epistémicos em marcha”. In: GROSFOGUEL, Ramón y HERNÁNDEZ, Roberto Almanza. Lugares descoloniales. Espacios de intervención em las Américas. Bogotá: Editorial Pontifícia Universidad Javeriana, 2012. p. 95-118.

Artigo recebido em 14 de maio de 2015.

Artigo aceito em 19 de junho de 2015. 